\title{
Modular robot used as a beach cleaner
}

\section{Robot modular usado como limpiador de playas}

\author{
Felippe Schmoeller da Roza ${ }^{1} \quad$ Vinicius Ghizoni da Silva ${ }^{1 *}$ \\ Patrick Jose Pereira $^{1} \quad$ Douglas Wildgrube Bertol ${ }^{1}$ \\ Recibido 17 de diciembre de 2015, aceptado 7 de marzo de 2016 \\ Received: December 17, 2015 Accepted: March 7, 2016
}

\begin{abstract}
This paper presents the development of a modular mobile robot platform for multiple purposes and its adaptation into a beach cleaner setup. The robot has a robust construction allowing it to endure several sorts of environments. In the presented configuration, the developed robot is able to autonomously collect cans using an excavator-like claw. In addition to detailing the system's design and construction, this paper presents the description of the developed embedded electronics modules, a motor closed-loop speed control system and the optical flow algorithms that allows the computer vision system to detect and avoid obstacles and track the cans to be collected.
\end{abstract}

Keywords: Mobile robots, robotics, computer vision, optical flow, speed control.

\section{RESUMEN}

Este artículo presenta el desarrollo de un robot modular multipropósito y su adaptación para ser usado en tareas de limpieza de playas. El robot presenta un diseño robusto, orientado a soportar las inclemencias de varios tipos de ambientes. Con la configuración presentada, el robot es capaz de recolectar autónomamente latas dispersas por el ambiente, utilizando una garra similar a la de una excavadora. Además de detallar el proyecto y el desarrollo del sistema, también es presentado una descripción de los módulos electrónicos desarrollados, el control de velocidad en malla cerrada utilizado y los algoritmos de flujo óptico, que mediante el uso de visión artificial permite evitar obstáculos y rastrear las latas que van a ser recolectadas.

Palabras clave: Robots modulares, robótica, visión artificial, flujo óptico, control de velocidad.

\section{INTRODUCTION}

The robotics field has been through revolutions with some technological progresses and the popularization of development boards, sensors, microcontrollers and other low-cost accessible electronic elements. Robots are the most common interest among undergraduate students of Control and Automation Engineering, at Federal University of Santa Catarina
(UFSC) in Brazil. Since 2002 the developments in robotics act as a constant at ROBOTA, a group of students (located at UFSC) that carries out research and development in autonomous mobile robotics.

More than ever, the development of mobile robots is accessible to undergraduate students and enthusiasts with easy access to the necessary parts. Also, a growing notion is that robotics can greatly assist

\footnotetext{
1 Department of Automation and Systems. Federal University of Santa Catarina. Brazil. E-mail: felippesroza@gmail.com; ghizoni28@gmail.com; patrickelectric@gmail.com; dwbertol@gmail.com

* Corresponding Author
} 
the learning process, as it can be used as an aid for understanding complex and difficult topics, popularizes the studies and its applications on the academic field [1].

Focused on robotics' competition from its beginning, winning multiple times the Latin American Robotics Competition (LARC) and the Brazilian Robotics Competition (CBR), ROBOTA now focuses on research and development, helping members and other students to widen their comprehension on robotics and promulgating the results throughout society.

Although there are multiple benefits into researching robotics, a possible disadvantage is that mobile robots can be somewhat expensive due to the fact that some tests could be dangerous for the robot's integrity, even though the results could be interesting for the field. While testing some extreme scenarios may help to advance in the area of robotics, it may as well damage the robot. Considering all the benefits and problems, ROBOTA decided to use off-the-shelf materials to develop more sturdy and versatile robots, being useful for teaching and research.

Several aspects of the robot's construction were closely related to structural robustness and versatility: the main objective was to develop a mobile robot that would last, being able to endure the actions, applications and errors commonly made during the researching process. Based on some research topics at UFSC's Department of Automation and Systems (DAS), it was found that the most appropriate features of the robot would be: to control the motors speed; differential wheel configuration; computer vision; and sturdy construction.

The robot has a modular construction, which lets it be more versatile, allowing adaptations for different usages and facilitates its assembly and its maintenance. The mechanical aspect of the robot has to grant the desired robustness and durability, as the robot would be used by both researchers and learning students. The electronics needs to allow the desired operation of a robust mechanical system and the possibility to apply techniques of process control, a huge aspect of the Control and Automation Engineering course. Also, an embedded computing framework has to allow the attachment of a camera and the processing of images, enabling the development of a computer vision system.

Some works developed at DAS served as inspiration for the project, as Douglas Bertol's master's degree dissertation: Contributions to the Development and Making of a Wheeled Mobile Robot [2], which served as guide during the project, answering some questions and presenting solutions to recurrent problems (and certifying some decisions taken on this project). Several other robotics projects and scientific papers were important to the present project: instead of starting from scratch, works as Balch's [3] inspired the specific claw design used; Fudge's [4] work presented some ideas for the storage compartment (and the robot itself) and confirmed that this work was on the right track.

During the robot's development, ROBOTA competed at a robotics challenge of designing a beach cleaner: the robot had to autonomously locate and collect cans distributed on a sandy soil. The competition would help to validate the robot's versatility, in which the developed modular robot had to operate with some attached modules allowing can collecting task to be accomplished.

\section{MECHANICAL MODELING}

As a modular robot, a requirement for the project was to develop it with a higher degree of structural robustness. To achieve this goal, the designed body of the robot was made of a $3 \mathrm{~mm}$ thick aluminum plate. Its dimensions are 350 x 410 x $240 \mathrm{~mm}$. Its construction and design, together with the materials used, grant the desired durability and endurance for a wide range of possible working environments.

\section{Main Unit}

The main unit is the body of the robot and continues the idea of a modular system, allowing the attachment of external actuators and sensors.

Firstly, the wheel configuration had to be chosen. Concerning the desired tasks that the robot should perform, a differential drive configuration was adopted due to its superior performance for some sorts of jobs and its mechanical simplicity [5].

The chosen wheel configuration is based on a fourwheel differential drive. Each pair of wheels is 
driven by an independent motor linked with a belt and pulley system, as depicted in Figure 1.

\section{Collecting System}

A frontal claw was designed and attached to the robot enabling it to collect cans from the ground. Its design was made in the shape of an excavator dumper, a well-known configuration used in dump trucks to collect trash. There are plenty of good gripper configurations for the specific task of cancollecting, as evidenced by Balch [3]. The chosen design is a power hungry configuration, but as the environment where the robot will operate has some challenges for can collecting (as semi-buried cans in the sand) and the battery used has plenty of useful energy, the choice was the most interesting one to be done.

The claw, shown in Figure 2, is composed by two different parts: the upper and lower one. They were designed separately, turning the assembly and disassembly of the claw an easier task. These two parts are connected by a Futaba S3003 servomotor, responsible for the claw's opening and closing movements. Making the claw with striped pieces of metal allows the robot to collect cans in an environment composed by

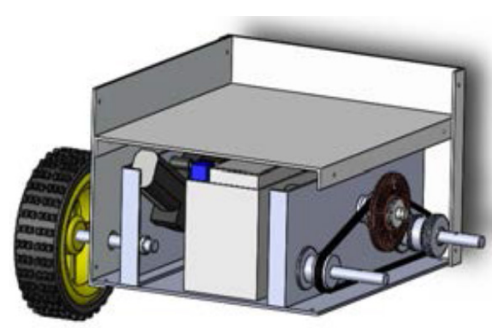

Figure 1. Side view of the robot, depicting the pulley system.

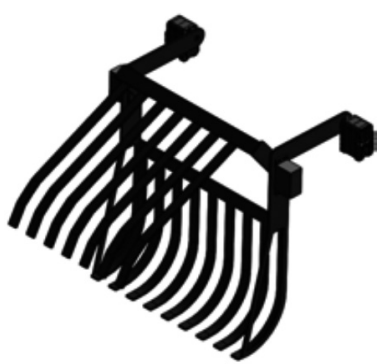

Figure 2. Isometric view of the claw (with the actuators). sandy or clayey soil, reducing the drag force and granting that not much sand is collected together with the cans.

The rising and lowering of the claw is granted by a pair of AX-12 servomotors. The chosen material for the claw manufacturing was a $2 \mathrm{~mm}$ thick aluminum plate.

\section{Storage Compartment}

The last mechanical module of the robot is the storage compartment. This module is positioned on top of the main unit allowing the claw to unload the collected cans inside of it. It has a pair of AX-12 servomotors responsible for turning out the collected material into an appropriate depot. It can be seen at the top of the robot in Figure 3, which shows an isometric view of robot.

The chosen material for the storage compartment manufacturing was a $2 \mathrm{~mm}$ thick MDF plate. Its dimensions are $211 \times 231 \times 211 \mathrm{~mm}$.

\section{COMPUTER VISION}

One of the most complex and crucial tasks of the proposed beach cleaner setup of the robot is the proper detection of cans and obstacles. A possible solution is to use an infrared depth sensor integrated to a camera, allowing a 3D reconstruction of the scenario. Kinect and Asus Xtion Pro are examples of systems that provide VGA resolution 3D measurement with high accuracy and affordable prices [6]. An intrinsic problem to this solution is that infrared sensors

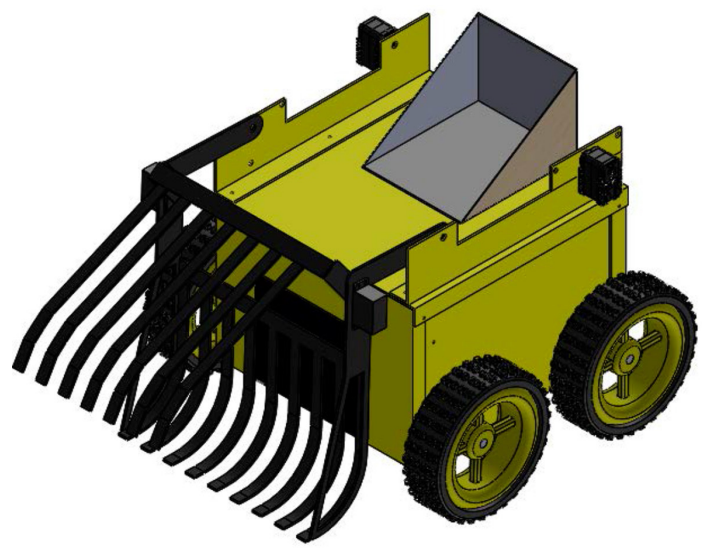

Figure 3. Robot with the beach cleaner setup. 
do not work well outdoors, turning it difficult to use these devices for activities such as can collecting at a beach [7].

Another possibility is to use optical flow to estimate the relative motion of the objects while the robot moves through the scenario. The optical flow can be obtained by methods that use two or more cameras [8], but as one of the objectives was to use low cost computers, this would bring problems with connectivity and processing the images of two cameras simultaneously. With a single camera, the applied algorithm has to be more robust to obtain a precise estimation of the optical flow.

Concerning those aspects, the chosen option was to use a single USB camera for solving the desired tasks. An on-board computer is responsible for collecting and processing the large amount of data required for the artificial vision system.

\section{HSV Color Space}

The regular Red-Green-Blue (RGB) color system is represented by a cube delimited in Cartesian color space, which linearly combines red, blue and green colors and it is widely used in software development, but is not a good choice for object detection because the RGB components are not distinctive enough to separate an object apart from another in an image [9].

The Hue-Saturation-Lightness (HSV) color space defines colors according to its hue, saturation and luminescence. It matches people's visual feeling better than RGB and other color spaces [10]. HSV representation is largely used in computer vision algorithms and is a better choice for object detection because usually each object in an image has a different hue level.

The HSV can be represented in a cylindrical colorspace. The hue parameter maps pure colors in an
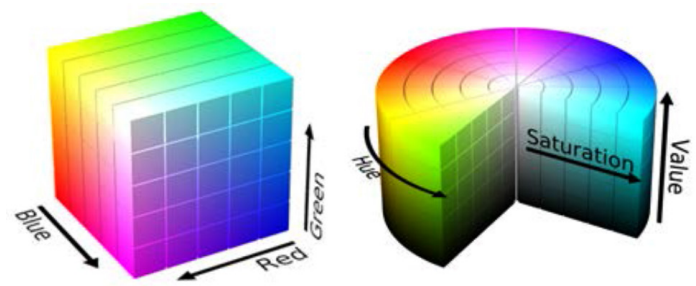

Figure 4. RGB (left) and HSV (right) color spaces. angular range, the value parameter represents the color brightness whereas the saturation indicates the amount of a certain color. RGB and HSV color spaces are shown in Figure 4.

To detect objects and identify cans that the robot has to collect, the obtained images are converted using an OpenCV library built-in function. Figure 5 shows the result of a RGB to HSV conversion.

After a preset of the RGB and HSV range for the specified color for detection, as seen in Figure 6, it is possible to obtain more precise detection results when the best 'candidates' of each image are merged.

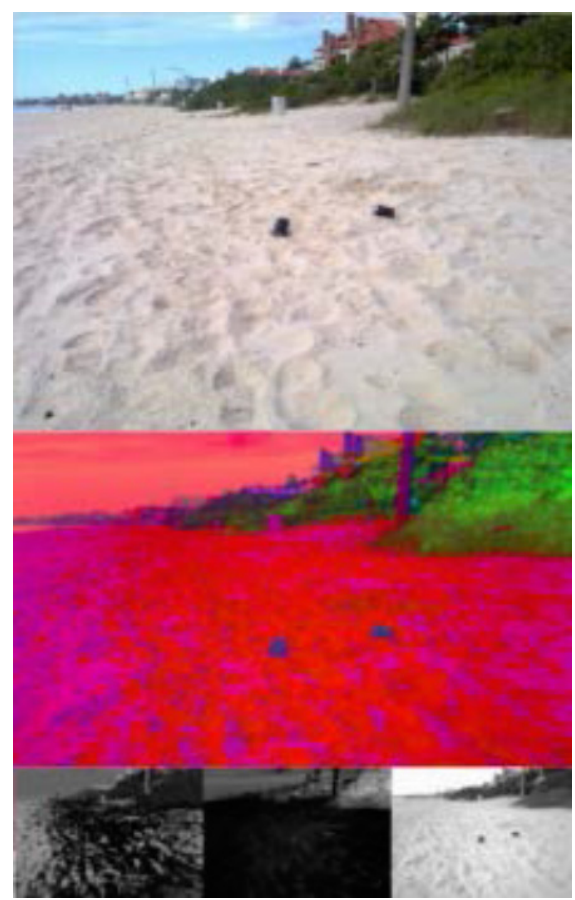

Figure 5. Camera image (top), converted to HSV (middle) and each HSV channel separately (bottom).

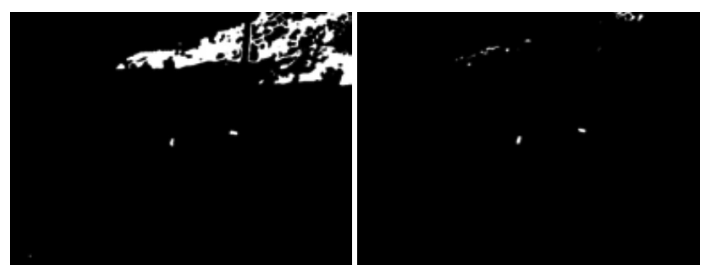

Figure 6. After RGB and HSV filtering, respectively. 


\section{Color Segmentation and Can Tracking}

After the conversion, both RGB and HSV images are used to detect the cans in the image. Firstly, the obtained images are converted to binary data, allowing binary operations with low computational cost. Then, a noise rejection filter is applied in both RGB and HSV samples. An AND bitwise operation is applied with the filtered RGB and HSV binary images. Working with both RGB and HSV and then applying the AND operation increases the probability to detect the objects despite the noise intrinsic to the image, making the results more reliable.

Detecting the edges of the binary images is a form to identify and classify the objects in the image and reduces the amount of processed data preserving the shape of the objects [11]. A well-known edge detector method is canny edge detector operator. Figure 7 shows the result of the canny edge method applied to an image. Afterward the edges are classified by its dimensions, and the position of the objects are identified.

\section{Optical flow and obstacle avoidance}

Optical flow is a good approach to estimate the apparent motion of the objects that are getting closer to the robot while it moves through the environment allowing the vision system to detect and avoid the obstacles.

Temporal changes in the position of the objects in the captured images manifest its movement, so detecting the objects and its position in each frame allows the vision system to calculate the object relative motion. An alternative is to estimate the optical flow through the motion of the edges [12]. The developed optical flow calculation algorithm classifies the objects by its edges obtained using the canny operator, then calculates the position of each object in the image and calculates its
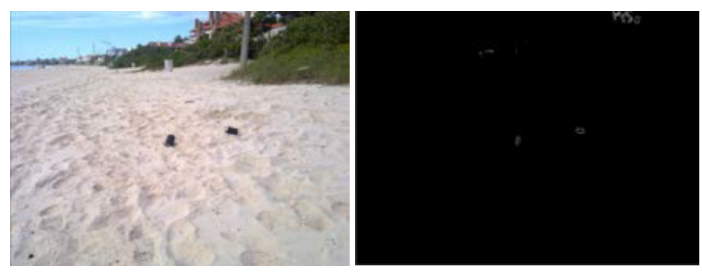

Figure 7. Edge detecting using canny operator example.

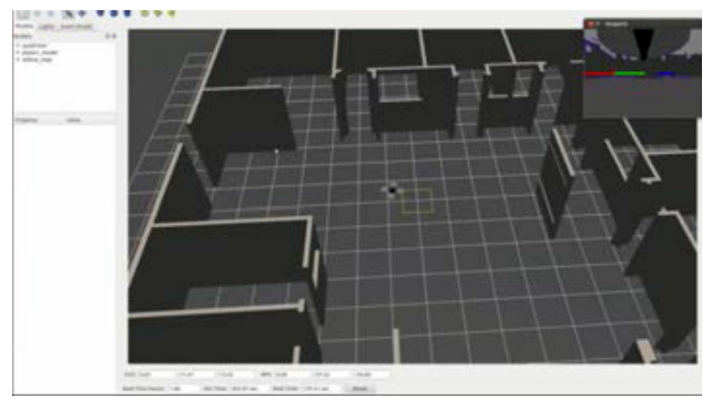

Figure 8. Simulation of the avoidance software on Gazebo simulator.

motion using the position and the time between each image capture.

The code was implemented and validated using ROS (Robotic Operating System), on the simulator Gazebo, as shown in Figure 8. The tests used the Hector quad rotor model, available on the ROS library, as it has an onboard camera to make the image processing possible.

After the simulations, the code was also implemented and tested on the real world as shown by Figure 9 . The bottom-left image shows the speed vectors of the point matrix that has moved from the first frame to the second. The bottom-right image represents the filtered and processed image, where the red area represents an obstacle to the avoidance algorithm. The algorithm makes the sum of the tree segments of the frame that contains the optical-flow vectors, detecting obstacles from the front, left or right of the robot.

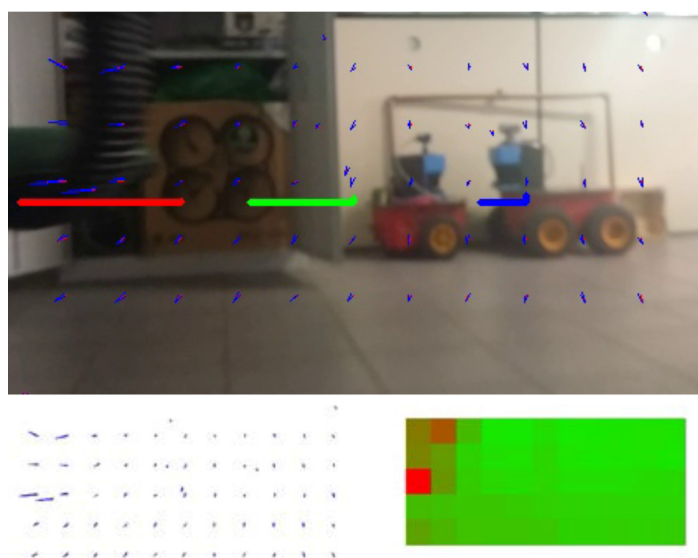

Figure 9. Obstacle avoidance with optical flow. 


\section{ELECTRONICS}

Since the mechanical construction focuses on a high structural robustness degree, the robot requires stronger actuators than a hobby servo or regular DC motor to move and accomplish tasks. For the differential drive, Mabuchi LC-578VA Automotive Power Window Lifter motors were chosen. Due to a large internal mechanical gear reduction, this motor presents high torque with relatively small packing. A downside is its high current drain and low efficiency. Motor specifications are displayed in Figure 10. A HS38A400 rotary encoder is attached to each motor shaft, allowing angular velocity measurement. Based on the electrical motor characteristics, a motor driver was designed. Also, a current and voltage measurement board was designed for battery management.

As stated before, the robot packs an embedded computer, built from off-the-shelf components: An Intel RH61 chipset-based motherboard, a Core 2 Duo processor and $4 \mathrm{~Gb}$ of 1333Mhz DD3 RAM. This amount of computational power allows image processing tasks and complex algorithms that cannot be handled by regular microcontrollers.

All system runs on a $12 \mathrm{~V}-12 \mathrm{Ah}$ lead-acid battery, similar to those found on regular motorcycles. Such battery allows high-current discharges, and is capable of supplying the required power for a substantial amount of time. A commercial MiniBox M4-ATX buck-boost DC-DC converter powers

\section{JC/LC-578VA-4720}

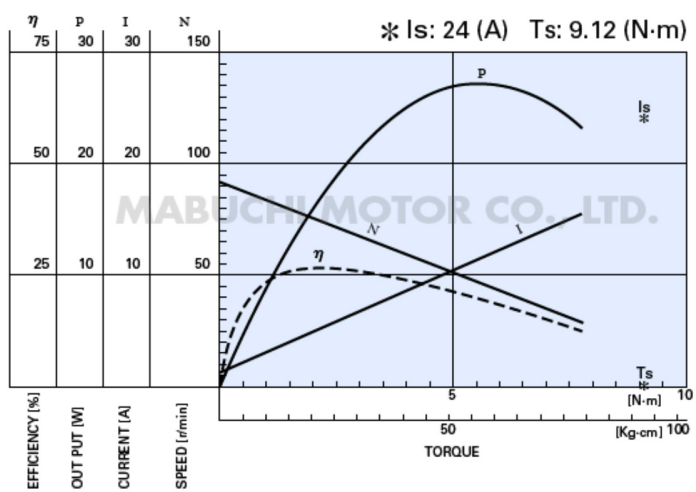

Figure 10. Mabuchi LC-578VA motor torque/current characteristics. the on-board computer from the battery in spite of voltage fluctuations.

\section{Motor Driver}

The motor driver was designed for individual DC motor control. For the power stage, a MOSFETbased H-Bridge, an usual circuit for DC motor control, was developed. The project foresees a board capable of holding 50A of continuous current, making it capable to support high power motors and increasing the versatility of the circuit. An embedded Atmega328 microcontroller is responsible for the motor's velocity control and uses its PWM (Pulse Width Modulation) outputs to do so. The board also supports dual-channel encoder reading.

An important aspect of the board's layout design was the decoupling of the power and control planes. Considering that the circuit is able to hold high current levels, such decoupling avoids that current peaks from the motors damage some sensible components. To grant the electrical decoupling, two physically isolated planes were designed, and optocouplers were used to keep the planes in isolation, switching the H-Bridge transistors without an electrical contact.

An ACS709 current sensor module, a Hall-effect sensor, is integrated in the board and connected to the embedded microcontroller allowing the motor current measurement. It holds over 2100VRMS at the input, isolating the output pin from the power plane and assuring the desired decoupling. The output pin gives a voltage proportional to the current that passes through the current sense input. This measurement grants a safe operation, because the microcontroller can disable the H-bridge if the current exceeds a safe value. Another benefit is that the torque of the motor can be estimated through the current measure, so a torque controller could be implemented.

The communication between the CPU and the local drivers is established through an UART (Universal Asynchronous Receiver/Transmitter) protocol.

\section{Current and Voltage Measurement Board}

Monitoring the battery state of charge (SOC) is vital for preventing a sudden stop from the robot if the battery is completely discharged. The SOC is a linear function of the open circuit voltage, but this method is not applicable to on line, continuous 
measurement because it requires a long stabilization period to an accurate indication [13].

The developed solution is based on combining current flux integration and open circuit voltage method, so that a more precise estimative of the SOC can be performed [14]. The circuit has a current sense module, which consists in two ACS709 boards in parallel. The designed printed circuit board layout is shown in Figure 11.

The voltage measurement is implemented using a circuit based on a voltage divider. The battery voltage is divided to $1 / 3$, and then a TL-072 operational amplifier is used for impedance compatibility.

An embedded Attiny 45 microcontroller is responsible to read the voltage from each ACS709 module and from the TL-072 output, allowing it to calculate the current drained from the battery and the battery voltage. An UART communication between the Attiny45 and the CPU allows the data transfer.

\section{MOTOR SPEED CONTROL}

Concerning that the designed robot has a modular construction and a wide range of applications, its speed control can be useful in almost every possible use of the robot. To design the controller it is

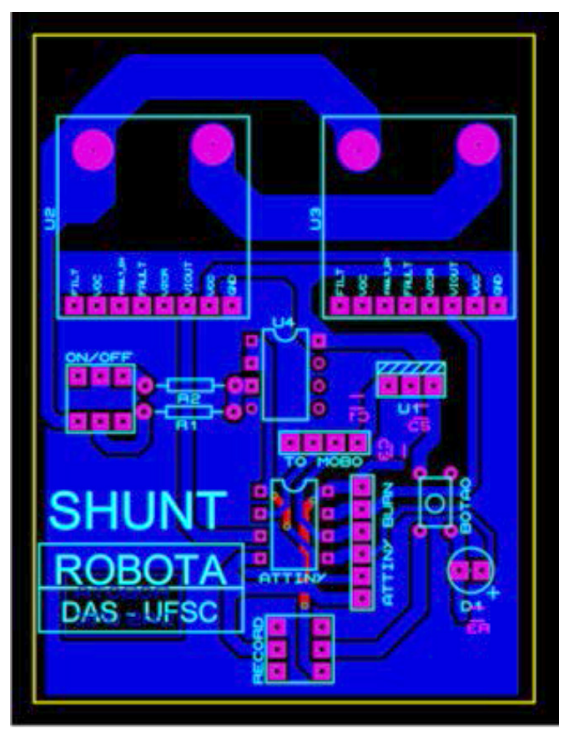

Figure 11. Current and Voltage Measurement Board. necessary to identify the dynamics of the motors. A well-known method is to model the system through a transfer function, a mathematical model that relates the input and the output of a linear time invariant system.

The transfer function of a system, $H(s)$, is the relation between the LaPlace transform of the output $Y(s)$ and the LaPlace transform of the input $U(s)$ :

$$
H(s)=\frac{Y(s)}{U(s)}
$$

There are many methods to identify an appropriate model. The chosen method was the step response, which consists in feeding the system with some known inputs (voltage applied to the motor) and observing the output (speed measured with the encoder). The real motor has many non-linearities, so the control system has to be robust enough so that it grants stability and reference tracking for all the range of operation.

Sometimes a simple but adequate model can be enough to represent the dynamics of the system allowing the project of the controller [15]. Some tests proven that a first order transfer function gives a sufficient approximation for the motors modeling, and a PID controller is enough for the speed control.

The block diagram presented in Figure 12 represents a simplified structure of the developed closed-loop system for the speed control motor. The chosen PID structure facilitates the implementation in the microcontrollers, for the individual gains that are disposed in parallel, then the gains calculated in continuous time are the same in discrete time, as commonly seen on industrial controllers.

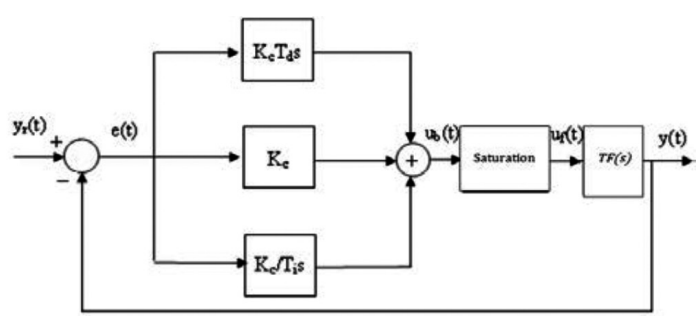

Figure 12. System's block diagram. 


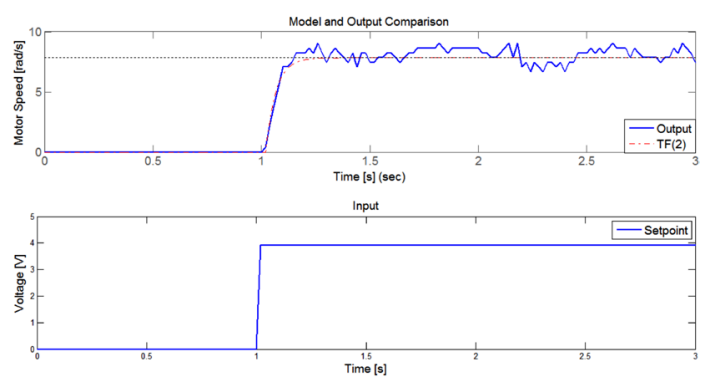

Figure 13. System's and model's response to a $3.92 \mathrm{~V}$ input.

A voltage step was applied for identifying the dynamics of the system. For the step-test used, the microcontroller applied $3.92 \mathrm{~V}_{\mathrm{RMS}}$ to the motor driver and the angular velocity was measured. The gathered data of the open-loop system response is shown in Figure 13, represented by the curve with the label 'Output'.

After acquiring the output response, it is possible to determine a first order transfer function that adequately models the system.

$$
T F(s)=\frac{k_{p} e^{-\theta s}}{\tau s+1}
$$

Defining the static gain $K_{p}$ requires an analysis of the measured output variation in relation to the variation of the input. Using the data acquired from the step-test the obtained value is:

$$
K p=\frac{\Delta Y}{\Delta U}=2
$$

The time when the system presents the $95 \%$ of its final value, called settling time and represented by $t_{5 \%}$, has a relation with the system's time constant.

$$
\tau=\frac{t_{5 \%}}{3}=0.0467
$$

There can be some dead-time, represented in Equation 2 by $e^{-\theta s}$. The system's dead-time can be approximated by 0.02 seconds. So, after the experiment and the calculations, the system can be adequately modeled by:

$$
T F(s)\left(=\frac{K_{p} e^{-\theta s}}{\tau s+1}=\frac{2 e^{-0.02 s}}{0.0467 s+1}\right)
$$

The response of the modeled system to the same input step is shown in Figure 13, in the curve with the label ' $\mathrm{TF}(2)$ '.

\section{PID tuning}

With the motor modeling done, it is now possible to design a controller for the system. There are many ways to tune its parameters, with the AMIGO tuning rule being a possible choice for the process [16].

Using the model described by Equation 5, it is possible to calculate the controller's parameters, as:

$$
\begin{gathered}
K_{p}=\left(\frac{1}{K_{p}}\right)\left(0,2+\frac{0.45 \tau}{\theta}\right) \\
T_{i}=\left(\frac{0.8 \tau+0.4 \theta}{0.1 \tau+\theta}\right) \theta \\
T_{d}=\frac{0.5 \tau \theta}{(\tau+0.3 \theta)}
\end{gathered}
$$

The developed controller is represented in continuous time, but the microcontroller, responsible for the closed loop control, works in discrete time, then the control law has to be discretized. As said before, the chosen PID structure allows a direct conversion to the discrete time, preserving the calculated gains.

\section{RESULTS}

The modular robot with the attached can collector and storage system was successfully designed and assembled. The body pieces were manufactured

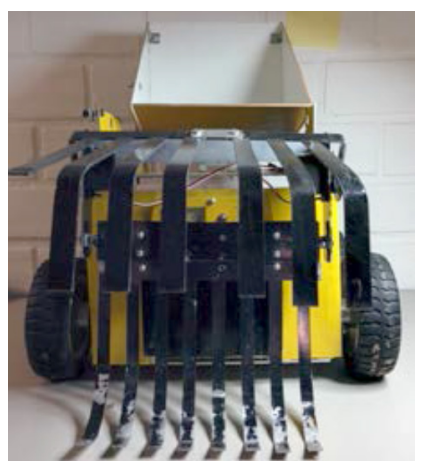

Figure 14. Robot with the can collecting setup. 
with laser cutting and folding of the aluminum plates. Figure 14 shows the robot with the attached claw and storage compartment that allows the can collecting.

The vision system's software was written as $\mathrm{C}++$, using openCV library functions. The can detecting result can be seen in Figure 15.

After localizing the can at the camera's range, the tracking system returns the position of the can related to a zero position reference in the middle of the bottom of the image. A vector is created to determine the distance and angle of the can in a reference of pixels. This vector is translated to the robot's hardware as a reference of angular and linear velocities, what makes the robot direct itself to the cans.

The electronic boards were designed using Proteus tool suite and manufactured using a MDX-40A Benchtop Milling Machine. The complete electric system can be seen in Figure 16.

The closed-loop angular velocity controller was written in $\mathrm{C}$ code and embedded in the driver's

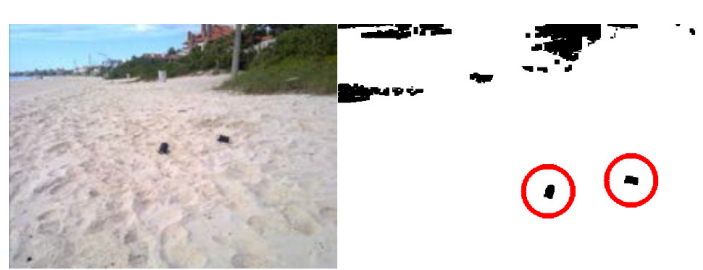

Figure 15. Image obtained by the camera (left) and the two black cans detected by the algorithm (right).

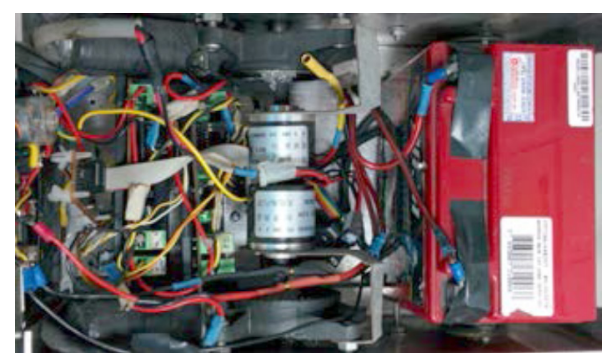

Figure 16. Electrical system: motor drivers, encoders, DC motors, shunt board and the $12 \mathrm{~V}$ battery. built-in microcontrollers. The velocity referencetracking experimental results can be seen in Figure 17. To validate the PID controller the controlled system received some Set points during certain lengths of time: a step of $1.5 \mathrm{rad} / \mathrm{s}$ for $2.45 \mathrm{~s}$, a step of $5.5 \mathrm{rad} / \mathrm{s}$ for $5 \mathrm{~s}$, a step of $3 \mathrm{rad} / \mathrm{s}$ for $7.4 \mathrm{~s}$, a step of $7.5 \mathrm{rad} / \mathrm{s}$ for $7.5 \mathrm{~s}$, a step of $8 \mathrm{rad} / \mathrm{s}$ for $7.5 \mathrm{~s}$ and ended with $0 \mathrm{rad} / \mathrm{s}$.

\section{CONCLUSION}

The desired structural robustness was achieved, with the robot being able to withstand a number of environmental adversities. With easy maintenance, considering that students could perform repairs on the robot without a guide manual, it is possible to affirm that the robot can outlast the time-span of some students' graduations. Although the robustness can be seen as a hard-to-measure concept, some facts allow the presented conclusion: the robot, built on 2012 , is still fully operational after a great number of beach operations (and recklessly done tests by freshmen students, that, among other conclusions, determined that the robot is stronger and sturdier than a standing adult and is even capable of knocking him down).

Preliminary tests proved that the claw was able to lift objects like soda and beer cans, empty or not. Even full 2 liters PET bottles were lifted by the robot's claw and its high-torque motors, but the storage compartment was not prepared for accommodating them.

The motor driver can withstand the challenges due the environmental adversities, being able to deal with the high electrical currents needed for the
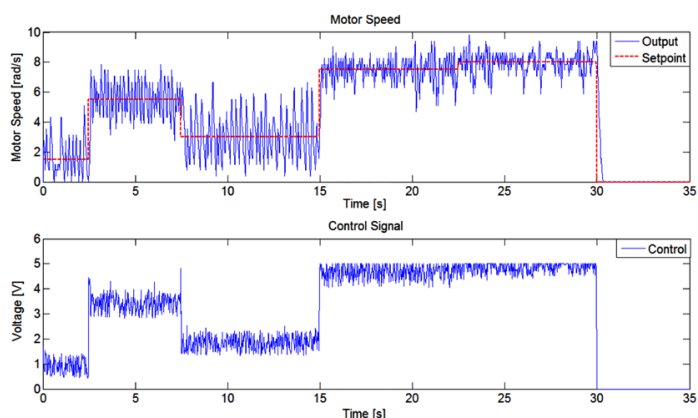

Figure 17. Closed-loop system response to a series of set-points. 
robot to move on situations where the wheels are somehow locked or stuck.

Successfully controlling the motors speed, the PID tuned by the AMIGO rule was adequate for the operation. It was interesting to verify that the speed control worked even without properly filtering the noises on the measured speed signals which normally appear in this type of system. Working well without a filter is another fact that allows the understanding of why PID controllers continue to be used so commonly on process of control. For further developments, other control techniques could give even more quality to the system's operation. The electronics and the system, as a whole, have characteristics that make implementing new solutions possible.

To validate the system's beach cleaning setup, some tests were made at a proper environment (at a beach with good illumination and not very thin sand).

The computer vision implementation was successful, detecting obstacles and cans even on a complex situation as a sunny beach with semi-buried cans.

The obstacles were only detectable when the robot was moving and using a regular sampling frequency, this due to the way it was implemented and the limitations of using only one camera to process the obstacle detection.

A performed test consisted of a can positioned in front of the robot, at a distance of 2 meters. The total time to reach the can and catch it was of 10 seconds. The tests allowed an estimation that only a few minutes would be necessary for the robot to clean a small area, with the operation limited to the storage compartment that can store 10 cans at a time.

A very interesting further development is to adapt all the system to the Robot Operating System (ROS), so popular among the robotics field. This will increase the robot's capabilities while making it accessible for the whole community.

As helping the robotics community is a big objective to the project, the developed robot can be seen as a useful prototype: with all the knowledge from the making of the robot, a second version with more accessible, but durable, materials will be made.

\section{ACKNOWLEDGEMENT}

The authors would like to direct a big thank to everyone who helped and supported them during the research and development of this project: the former members of ROBOTA Martin, Izabele, Marcus and Arthur; to Guilherme Vianna Raffo, who was a great mentor and to Professor Julio Elias Normey-Rico who provided most of the materials and financial support (and believed in our ideas and intentions for this project).

\section{REFERENCES}

[1] J. Pio, T. Castro and A. Júnior. "A robótica móvel como instrumento de apoio à aprendizagem de computação". In Simpósio Brasileiro de Informática na Educação - SBIE - UNB/UCB - 2006, pp. 497-506, Aug. 2006.

[2] D.W. Bertol. "Contribuições ao desenvolvimento e construção de um robô com rodas". In Dissertação (Mestrado) Universidade Federal de Santa Catarina, Centrol Tecnológico. Programa de PósGraduação em Engenharia Elétrica, pp. Florianópolis, xxiii, p. 224, March 2009.

[3] T. Balch, G. Boone, T. Collins, H. Forbes, D. MacKenzie, and J. Santamaña. "Io, ganymede, and callisto: A multiagent robot trash-collecting team". AI Magazine Vol. 16 $\mathrm{N}^{\circ}$ 2, pp. 31-51. Summer 1995.

[4] E. Fudge, G. Fox, J. Maham and E. Williams, "Trash can robot: High school robotics initiative". 2013 IEEE Frontiers in Education Conference (FIE), pp. S3D20-24. 2013.

[5] S. He. "Feedback control design of differential-drive wheeled mobile robots", in Advanced Robotics, 2005. ICAR '05, 12th International Conference on, pp. 135-140. July 2005.

[6] R. Yang, Y.H. Chan, R. Gong, M. Nguyen, A. Strozzi, P. Delmas, G. Gimel'farb and R. Ababou. "Multi-kinect scene reconstruction: Calibration and depth inconsistencies". In Image and Vision Computing New Zealand (IVCNZ). 28th International Conference, pp. 47-52. Nov 2013. 
[7] K. Amma, Y. Yaguchi, Y. Niitsuma, T. Matsuzaki and R. Oka. "A comparative study of gesture recognition between RGB and HSV colors using time-pace continuous dynamic programming". In Awareness Science and Technology and Ubi-Media Computing (iCAST-UMEDIA), International Joint Conference, pp. 185-191. Nov 2013.

[8] S. Vedula, P. Rander, R. Collins and T. Kanade. "Three-dimensional scene flow". Pattern Analysis and Machine Intelligence, IEEE Transactions. Vol. 27, pp. 475-480. March 2005.

[9] I. Awaludin, P. Hidayatullah, J. Hutahaean and D. Parta. "Detection and object position measurement using computer visión on humanoid soccer". In Information Technology and Electrical Engineering (ICITEE). International Conference, pp. 88-92. Oct. 2013.

[10] M. Moghimi and H. Pourghassem. "Shadow detection base don combinations of HSV color space and ortogonal transformation in surveillance videos". In Intelligent Systems (ICIS), Iranian Conference, pp. 1-6. Feb. 2014.

[11] R. Sidhu. "Improved canny edge detector in various color spaces". In Reliability, Infocom
Technologies and Optimization (ICRITO) (Trends and Future Directions), 3rd International Conference, pp. 1-6. Oct. 2014.

[12] G.-J. Kim, K.-Y. Eom, M.-H. Kim, J.-Y. Jung and T.-K. Ahn. "Automated measurement of crowd density base don edge detection and optical flow". In Industrial Mechatronics and Automation (ICIMA), 2nd International Conference. Vol. 2, pp. 553-556. 2010.

[13] K. Kuluay, Y. Cadirci, Y. Ozkazanc and I. Cadirci. "A new online state-of-charge estimation and monitoring system for sealed lead-acid batteries in telecommunication power supplies". Industrial Electronics, IEEE Transactions. Vol. 52, pp. 1315-1327. Oct. 2005.

[14] D. Deepti and V. Ramanarayanan. "State of charge of lead acid battery". In Power Electronics, 2006. IICPR 2006, India International Conference, pp. 89-93. Dec 2006.

[15] A.A.R. Coelho and L.S. Coelho. "Identificação de Sistemas dinámicos lineares". Ed. Da UFSC, pp. 181. Florianópolis, Brasil. 2004.

[16] K. Åström and T. Hägglund. "Revisiting the ziegler-nichols step response method for PID control". In Journal of Process Control Vol. 14, Issue 6, pp. 635-650. Sep. 2004. 